\title{
Phyllosphere epiphytic and endophytic fungal community and network structures differ in a tropical mangrove ecosystem
}

\author{
Hui Yao ${ }^{1,2}$, Xiang Sun ${ }^{1}$, Chao He ${ }^{3}$, Pulak Maitra ${ }^{1,2}$, Xing-Chun $\mathrm{Li}^{1}$ and Liang-Dong Guo ${ }^{1,2^{*}}$ (D)
}

\begin{abstract}
Background: Revealing the relationship between plants and fungi is very important in understanding biodiversity maintenance, community stability, and ecosystem functioning. However, differences in the community and network structures of phyllosphere epiphytic and endophytic fungi are currently poorly documented. In this study, we examined epiphytic and endophytic fungal communities associated with the leaves of six mangrove species using Illumina MiSeq sequencing of internal transcribed spacer 2 (ITS2) sequences.

Results: A total of 635 operational taxonomic units (OTUs) of endophytic and epiphytic fungi were obtained at a 97\% sequence similarity level; they were dominated by Dothideomycetes and Tremellomycetes. Plant identity had a significant effect on the OTU richness of endophytic fungi, but not on epiphytic fungi. The community composition of epiphytic and endophytic fungi was significantly different, and plant identity had a greater effect on endophytic fungi than on epiphytic fungi. Network analysis showed that both epiphytic and endophytic network structures were characterized by significantly highly specialized and modular but lowly connected and anti-nested properties. Furthermore, the endophytic network had higher levels of specialization and modularity but lower connectance and stronger anti-nestedness than the epiphytic network.
\end{abstract}

Conclusions: This study reveals that the phyllosphere epiphytic and endophytic fungal communities differ, and plant identity has a greater effect on the endophytic fungi than on epiphytic fungi. These findings demonstrate the role of host plant identity in driving phyllosphere epiphytic and endophytic community structure.

Keywords: Endophytic fungi, Epiphytic fungi, Illumina MiSeq sequencing, ITS2, Mangroves, Network structure

\section{Background}

The interaction between plant and microbial communities drives the maintenance of biodiversity, community stability, and ecosystem functioning [1]. Phyllosphere fungi are an important component of microbial communities; they include both epiphytic fungi inhabiting leaf surfaces and endophytic fungi living asymptomatically within leaves, and are of high species diversity and play major roles in ecosystem functions [2-5]. For example, endophytic fungi can promote plant growth and resistance to biotic and abiotic stresses, such as pathogens,

\footnotetext{
* Correspondence: guold@im.ac.cn

'State Key Laboratory of Mycology, Institute of Microbiology, Chinese Academy of Sciences, Beijing 100101, People's Republic of China

${ }^{2}$ College of Life Sciences, University of Chinese Academy of Sciences, Beijing

100049, People's Republic of China

Full list of author information is available at the end of the article
}

drought, and salinity $[2,6,7]$. In addition, epiphytic and endophytic fungi can contribute to leaf litter decomposition and play an important role in recycling carbon and nutrients in ecosystems [8-10]. Thus, elucidating the relationship between plants and phyllosphere epiphytic and endophytic fungi is of great importance if we are to understand biodiversity maintenance, community stability, and ecosystem functioning.

Phyllosphere epiphytic and endophytic fungi occupy two distinct microenvironments: epiphytic fungi are in contact with the external environment, and depend on nutrients deposited on leaves from the atmosphere or those exuded from leaves [11], whereas endophytic fungi are in contact with the plant's inner environment and absorb nutrients from host tissues [12]. Plants are therefore presumably able to exert more control over the fungal colonization of internal tissues than that of exterior 
surfaces [13]. For example, some studies have shown that plant identity significantly affects endophytic fungal diversity and community composition [14-18]. By contrast, some studies have demonstrated that plant identity has no or weak effects, on epiphytic fungal diversity and community composition [19, 20]. Furthermore, previous studies have shown that the diversity and community composition of phyllosphere epiphytic and endophytic fungi are different [13, 21-23].

Disentangling the interactions of plants and fungi using ecological network analysis can give us a deeper understanding of the mechanisms underlying species coexistence and ecosystem stability [24, 25]. Among the main structural properties of networks, the nestedness concept describes a particular pattern of interaction in which the more specialist species interact only with proper subsets of those species interacting with the more generalists [26]. On the other hand, modularity is a measure of the extent to which the network is structured as cohesive subgroups of nodes (modules), in which the density of interactions is higher within subgroups than among subgroups [27]. A nested network architecture can make a community more robust to random extinctions [28] and enhance biodiversity by reducing interspecific competition and facilitating species coexistence [29]. By contrast, modular organization can increase overall network stability, particularly by limiting the impact of perturbations within a single module and minimizing impacts on other modules, and therefore buffering communities against secondary extinctions following disturbance [30].

Recently, based on re-analysis of previously published datasets of biotrophic plant-fungal associations, it has been suggested that nestedness decreases but modularity increases with increasing specificity [25], whereas nestedness increases but modularity decreases with increasing connectance [31]. However, most previous network studies on fungi have focused mainly on belowground mycorrhizal mutualistic networks, which vary among different mycorrhizal types and different ecosystems [32-40]. By contrast, the network structure of plants with endophytic and epiphytic fungi is less well documented [31, 41, 42]. For example, Ikeda et al. [41] revealed that the network of endophytic Xylariaceae and woody plants in Japan showed significant specialization. Chagnon et al. [42] found that the endophytic networks of plants were less nested, less connected, and more modular than endolichenic networks across five sites in North America and suggested that plant hosts could select more strongly than lichens for a specific subset of fungal partners. In addition to interaction types, interaction intimacy (i.e., the degree of biological associations between partners) can lead to differences in network organization; that is, increasing intimacy can promote specialization, leading to networks characterized by compartmentalization, whereas weak intimacy can lead to nested networks [43].

Mangrove forests are unique intertidal ecosystems confined to the subtropical and tropical regions and they contain about 70 plant species of 27 genera in 20 families, occupying ca. $137,760 \mathrm{~km}^{2}$ all over the world [44]. Mangrove forests have very important ecological and economical values, such as promoting sludge sedimentation, protecting coastlines from hurricanes, and providing breeding sites for many animal species and materials (e.g., fuel, timber, and tannins) for human [44]. Although many studies have been conducted on the endophytic fungi of mangroves [45, 46], there have been no studies comparing endophytic and epiphytic fungal communities.

For this reason, in order to reveal differences in the community and network structures of epiphytic and endophytic fungi, we examined epiphytic and endophytic fungal communities associated with the leaves of six mangrove species (Aegiceras corniculatum, Avicennia marina, Bruguiera gymnorrhiza, Kandelia candel, Rhizophora stylosa, and Excoecaria agallocha) in south China using Illumina MiSeq sequencing techniques. Because epiphytic and endophytic fungi occupy two distinct micro-habitats, resulting in the intimacy of interaction between plants and endophytic fungi being stronger than that between plants and epiphytic fungi, we therefore hypothesize that the communities of epiphytic and endophytic fungi differ, and plant identity has a greater effect on endophytic fungi than on epiphytic fungi. We also used network analysis to test the hypothesis that the endophytic network is more specialized and modular but less nested and connected than the epiphytic network in a mangrove system.

\section{Results}

\section{Characterization of Illumina sequencing data}

After removing 1,221,272 sequences that belong to low-quality, non-fungi, potential chimeras and singletons, the remaining non-chimeric fungal internal transcribed spacer 2 (ITS2) sequences (3,083,632 in total) were clustered into 1160 non-singleton operational taxonomic units (OTUs) at a 97\% sequence similarity level. Of these 1160 OTUs, 826 (2,525,065 reads) were identified as fungal. From this dataset, we removed the OTUs with fewer than 10 reads, leaving 639 fungal OTUs. As the fungal read numbers ranged from 6827 to 49,955 across the 96 samples, the read number was normalized to 6827 , resulting in a normalized dataset comprising 635 fungal OTUs (655,392 reads). The fungi represented included 456 Ascomycota, 169 Basidiomycota, 1 Cryptomycota, and 9 unknown fungi (Additional file 1: Table S1), and dominated by Dothideomycetes and Tremellomycetes both in the epiphytic and endophytic fungal communities, with 
varying relative abundance among different mangrove species (Fig. 1a, b). The 42 relatively abundant OTUs $(>1000$ reads) accounted for $88.4 \%$ of the reads for epiphytic fungi, and the 41 relatively abundant OTUs (>1000 reads) accounted for $87.3 \%$ of the reads for endophytic fungi (Additional file 2: Figure S1). For both epiphytic and endophytic fungi, rarefaction curves for the observed OTUs in the six plant species showed no signs of reaching asymptotes, suggesting that further sampling would recover more OTUs (Additional file 2: Figure S2).

\section{Richness of epiphytic and endophytic fungi}

The OTU richness of epiphytic and endophytic fungi respectively was $39.0 \pm 15.2$ and $67.4 \pm 15.4$ in A. corniculatum, $41.5 \pm 5.7$ and $74.0 \pm 21.1$ in A. marina, $47.0 \pm$ 14.0 and $52.0 \pm 17.3$ in B. gymnorrhiza, $44.1 \pm 11.0$ and $93.9 \pm 28.9$ in E. agallocha, $43.6 \pm 7.9$ and $42.8 \pm 6.6$ in K. candel, and $41.0 \pm 12.2$ and $57.4 \pm 29.8$ (means \pm SD) in R. stylosa (Fig. 2). Kruskal-Wallis test and one-way analysis of variance (ANOVA) revealed that plant identity had a significant effect on the OTU richness of endophytic fungi $\left(\chi^{2}=17.849, P=0.003\right)$, but not on that of epiphytic fungi $\left(F_{5,42}=0.654, P=0.660\right)$. For example, the OTU richness of endophytic fungi was significantly higher in E. agallocha than in B. gymnorrhiza and $K$. candel, and higher in A. marina than in $K$. candel (Fig. 2).

\section{Community composition of epiphytic and endophytic fungi}

Of the 635 fungal OTUs, 119 (18.7\% of the total OTUs) were specific epiphytic fungi, 259 (40.8\%) were specific endophytic fungi, and 257 (40.5\%) shared between them (Additional file 2: Figure S3). For example, members of genera Curreya, Peniophora, and Cytospora were exclusively epiphytic, whereas members of genera Auriculibuller, Yamadazyma, Pseudoplectania, and Simplicillium were exclusively endophytic (Additional file 1: Table S1). Besides, the relative abundances of some abundant OTUs were significantly different between epiphytic and endophytic fungi in plant species (Additional file 3: Table S2).

The heatmap revealed that the occurrence of some relatively abundant epiphytic and endophytic fungal OTUs was biased among plant species (Fig. 3a, b). For example, of the epiphytic fungi, three OTUs (Hypocreales OTU186, Pseudocercospora OTU461, and Rhodotorula OTU566) were distributed mainly in A. marina, while eight OTUs (Phyllosticta OTU211, Uwebraunia OTU437, Dothideomycetes OTU440, Mycosphaerellaceae OTU441, Zasmidium OTU453, Pseudocercospora OTU491, Ascomycota OTU502, and Botryosphaeriaceae OTU523) occurred mainly in E. agallocha (Fig. 3a). Among the endophytic fungi, five OTUs (Acaromyces OTU16, Cladosporium OTU48 and OTU504, Tremellales OTU455, and Davidiellaceae OTU466) occurred mainly in $A$.

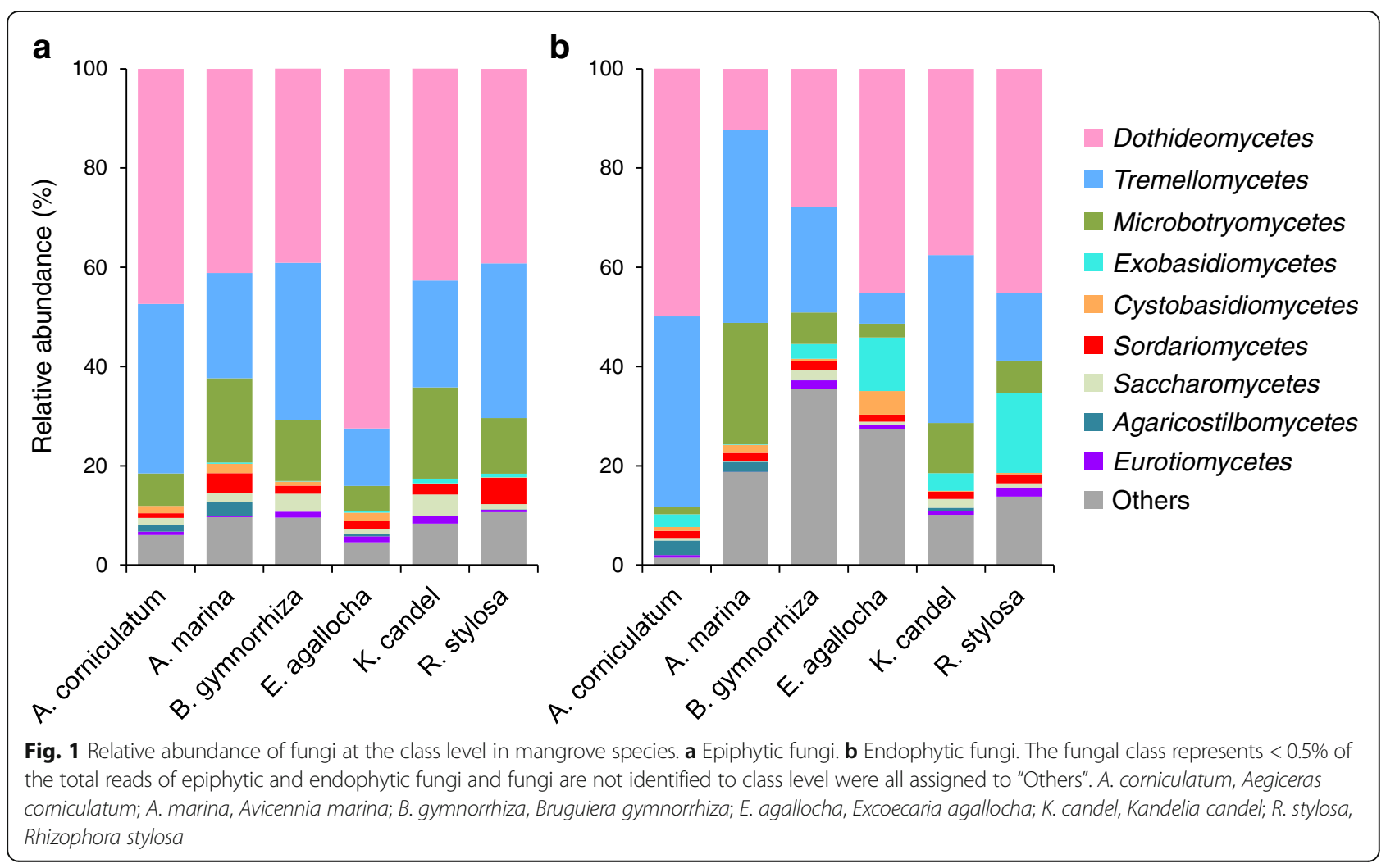




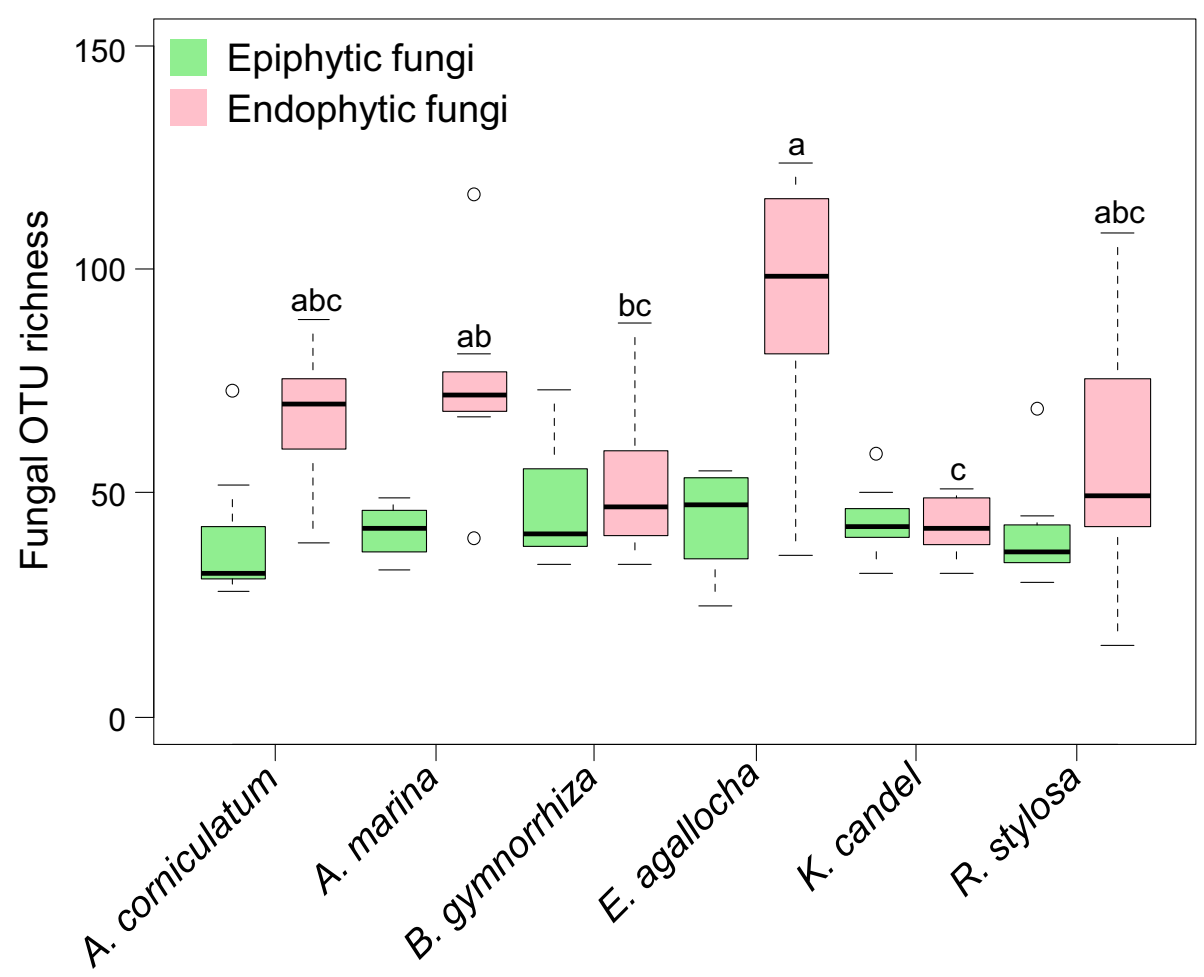

Fig. 2 Operational taxonomic unit (OTU) richness of epiphytic and endophytic fungi in mangrove species. The black line inside each box represents the median value $(n=8)$. Kruskal-Wallis test and one-way ANOVA revealed that plant identity had a significant effect on the OTU richness of endophytic fungi $\left(X^{2}=17.849, P=0.003\right)$, but not on that of epiphytic fungi $\left(F_{5,42}=0.654, P=0.660\right)$. Bars without shared letters indicate significant differences in the OTU richness of the endophytic fungi among mangrove species determined by Conover's test at $P<0.05$. A. corniculatum, Aegiceras corniculatum; $A$. marina, Avicennia marina; B. gymnorrhiza, Bruguiera gymnorrhiza; E. agallocha, Excoecaria agallocha; K. candel, Kandelia candel; R. stylosa, Rhizophora stylosa

corniculatum, nine OTUs (Erythrobasidium OTU11, Dothideomycetes OTU433, Jaminaea OTU435 and OTU439, Uwebraunia OTU437, Mycosphaerellaceae OTU443, Zasmidium OTU453, Pleosporales OTU484, and Sporobolomyces OTU513) were present mainly in $E$. agallocha, and five OTUs (Phaeoramularia OTU33, Dothideomycetes OTU440, Toxicocladosporium OTU485, Neodevriesia OTU501, and Meira OTU595) occurred mainly in $R$. stylosa (Fig. 3b). In addition, indicator species analysis showed that there were 5 epiphytic fungal indicator OTUs, OTU461 (Pseudocercospora) for A. marina and 4 (Phyllosticta OTU211, Botryosphaeriaceae OTU216 and OTU523, and Pseudocercospora OTU491) for E. agallocha; by contrast, there were 30 endophytic fungal indicator OTUs, with 10 for A. corniculatum, 4 for A. marina, 11 for E. agallocha, and 5 for $R$. stylosa (OTUs taxonomic positions see Table 1).

The non-metric multidimensional scaling (NMDS) ordination revealed that the community composition of epiphytic and endophytic fungi was significantly different (Fig. 4a). Furthermore, the epiphytic fungal community composition in E. agallocha was significantly different from that in the other five plant species, but no significant difference among these latter five plant species was observed (Fig. 4b). The endophytic fungal community composition was significantly different in the six plant species, except for between B. gymnorrhiza and K. candel and between B. gymnorrhiza and R. stylosa (Fig. 4c). The permutational multivariate analysis of variance analysis (PerMANOVA) also indicated that the community composition of epiphytic and endophytic fungi was significantly different $\left(F=6.435, R^{2}=0.064, P=0.001\right)$. Furthermore, plant identity significantly affected the community composition of both endophytic fungi and epiphytic fungi, with a greater effect on endophytic fungi than on epiphytic fungi, as the variation explained by plant identity was higher for the endophytic fungal community ( $F=$ $\left.8.125, R^{2}=0.492, P=0.001\right)$ than for the epiphytic fungal community $\left(F=2.648, R^{2}=0.240, P=0.001\right)$.

Preference of plants and epiphytic and endophytic fungi Host/fungus preference analysis showed that five plant species (A. corniculatum, A. marina, E. agallocha, K. candel, and R. stylosa) had significant preferences for epiphytic fungi (Fig. 5a), but all six plant species showed significant preferences for endophytic fungi (Fig. 5b). In addition, 3 (Phyllosticta OTU211, Ascomycota OTU502, and Botryosphaeriaceae OTU523) out of the 42 relatively abundant 


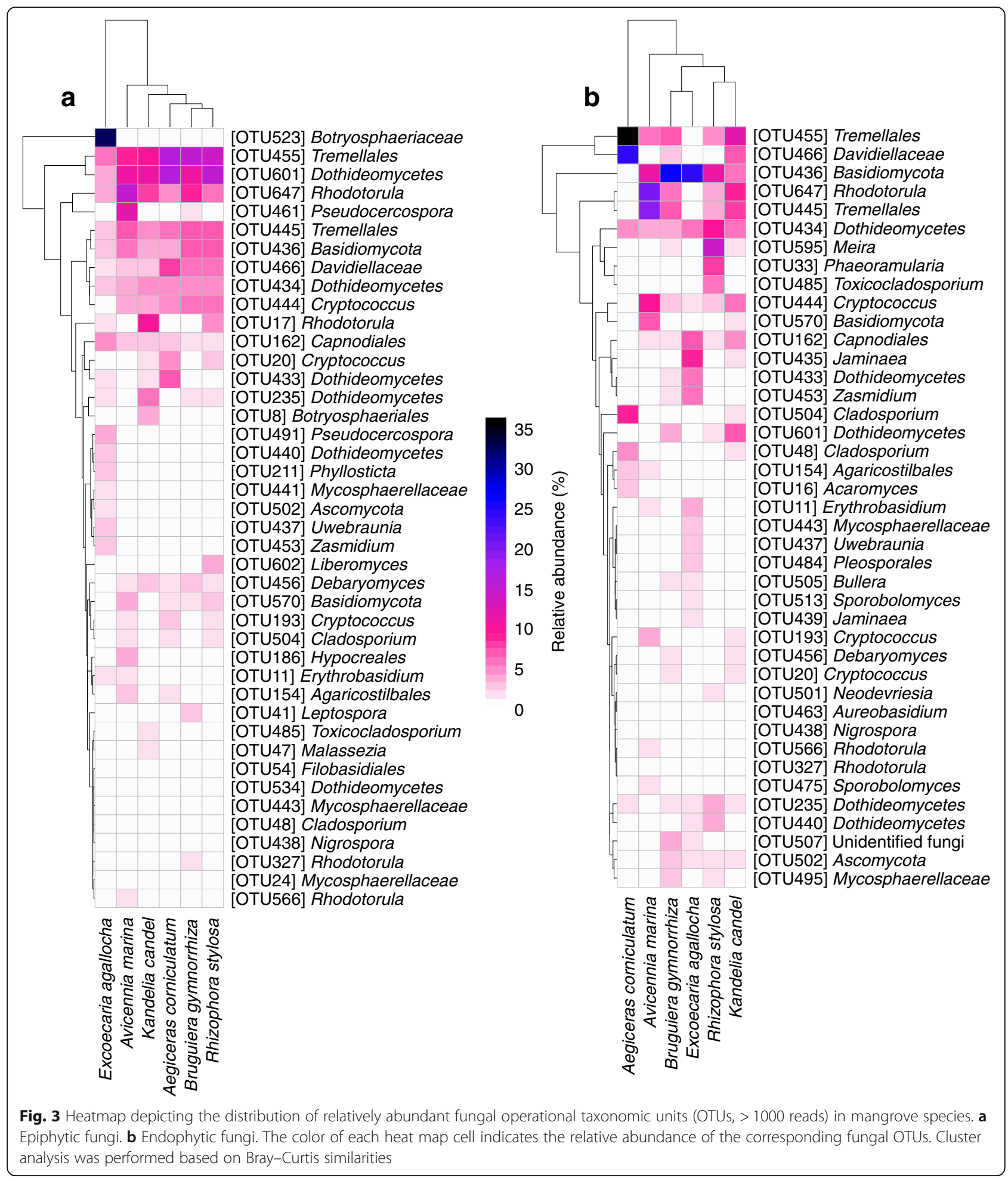

epiphytic fungal OTUs showed significant host preferences (Fig. 5a). By contrast, 32 out of 41 relatively abundant endophytic fungal OTUs displayed significant host preferences, such as OTU16 (Acaromyces), OTU433, OTU440 and OTU601 (Dothideomycetes), OTU445 and OTU455
(Tremellales), OTU453 (Zasmidium), OTU466 (Davidiellaceae), and OTU570 (Basidiomycota) (Fig. 5b). In our dataset, 8 out of 240 pairs of plant species and epiphytic fungi showed significantly strong preferences (two-dimensional preferences $(2 D P)>2.4)$; they included the pairs $E$. 
Table 1 Epiphytic and endophytic fungal indicator operational taxonomic units (OTUs) in mangrove species

\begin{tabular}{|c|c|c|c|c|}
\hline$\overline{\text { OTU }}$ & Taxonomic position & Mangrove species & Indval value (>0.6) & $P$ value \\
\hline \multicolumn{5}{|l|}{ Epiphyte } \\
\hline OTU461 & Pseudocercospora & Avicennia marina & 0.612 & 0.015 \\
\hline OTU211 & Phyllosticta & Excoecaria agallocha & 0.625 & 0.001 \\
\hline OTU216 & Botryosphaeriaceae & E. agallocha & 0.722 & 0.002 \\
\hline OTU491 & Pseudocercospora & E. agallocha & 0.687 & 0.001 \\
\hline OTU523 & Botryosphaeriaceae & E. agallocha & 0.863 & 0.001 \\
\hline \multicolumn{5}{|l|}{ Endophyte } \\
\hline OTU29 & Neodevriesia & Aegiceras corniculatum & 0.625 & 0.001 \\
\hline OTU48 & Cladosporium & A. corniculatum & 0.765 & 0.001 \\
\hline OTU49 & Pestalotiopsis & A. corniculatum & 0.703 & 0.001 \\
\hline OTU109 & Capnodiales & A. corniculatum & 0.971 & 0.001 \\
\hline OTU130 & Capnodiales & A. corniculatum & 0.820 & 0.001 \\
\hline OTU355 & Agaricostilbales & A. corniculatum & 0.624 & 0.001 \\
\hline OTU356 & Dothideomycetes & A. corniculatum & 0.944 & 0.001 \\
\hline OTU357 & Cladosporium & A. corniculatum & 0.780 & 0.001 \\
\hline OTU466 & Davidiellaceae & A. corniculatum & 0.692 & 0.001 \\
\hline OTU504 & Cladosporium & A. corniculatum & 0.814 & 0.001 \\
\hline OTU15 & Capnodiales & Avicennia marina & 0.721 & 0.001 \\
\hline OTU25 & Basidiomycota & A. marina & 0.760 & 0.001 \\
\hline OTU102 & Sporidiobolales & A. marina & 0.861 & 0.001 \\
\hline OTU570 & Basidiomycota & A. marina & 0.619 & 0.001 \\
\hline OTU11 & Erythrobasidium & Excoecaria agallocha & 0.685 & 0.001 \\
\hline OTU433 & Dothideomycetes & E. agallocha & 0.605 & 0.001 \\
\hline OTU435 & Jaminaea & E. agallocha & 0.822 & 0.001 \\
\hline OTU437 & Uwebraunia & E. agallocha & 0.856 & 0.001 \\
\hline OTU439 & Jaminaea & E. agallocha & 0.919 & 0.001 \\
\hline OTU443 & Mycosphaerellaceae & E. agallocha & 0.658 & 0.001 \\
\hline OTU453 & Zasmidium & E. agallocha & 0.675 & 0.001 \\
\hline OTU484 & Pleosporales & E. agallocha & 0.686 & 0.001 \\
\hline OTU494 & Mycosphaerellaceae & E. agallocha & 0.747 & 0.001 \\
\hline OTU499 & Erythrobasidiales & E. agallocha & 0.625 & 0.002 \\
\hline OTU516 & Symmetrospora & E. agallocha & 0.658 & 0.001 \\
\hline OTU33 & Phaeoramularia & Rhizophora stylosa & 0.842 & 0.001 \\
\hline OTU42 & Zymoseptoria & R. stylosa & 0.625 & 0.001 \\
\hline OTU485 & Toxicocladosporium & R. stylosa & 0.722 & 0.001 \\
\hline OTU538 & Dothideomycetes & R. stylosa & 0.609 & 0.001 \\
\hline OTU595 & Meira & R. stylosa & 0.820 & 0.001 \\
\hline
\end{tabular}

agallocha and OTU211 (Phyllosticta) and A. marina and OTU570 (Basidiomycota) (Fig. 5a). By contrast, 23 out of 228 pairs of plant species and endophytic fungi were observed to have significantly strong preferences $(2 D P>2.6)$, such as A. corniculatum and OTU16 (Acaromyces), E. agallocha and OTU437 (Uwebraunia), and R. stylosa and OTU595 (Meira) pairs (Fig. 5b).
Network structure of plant-epiphytic and plantendophytic fungi

The network of plants and epiphytic and endophytic fungi is shown in Fig. 6a, b. The network structure of both plant-epiphytic and plant-endophytic fungi was highly specialized and modular but showed lowly connected and anti-nested properties. In particular, the 

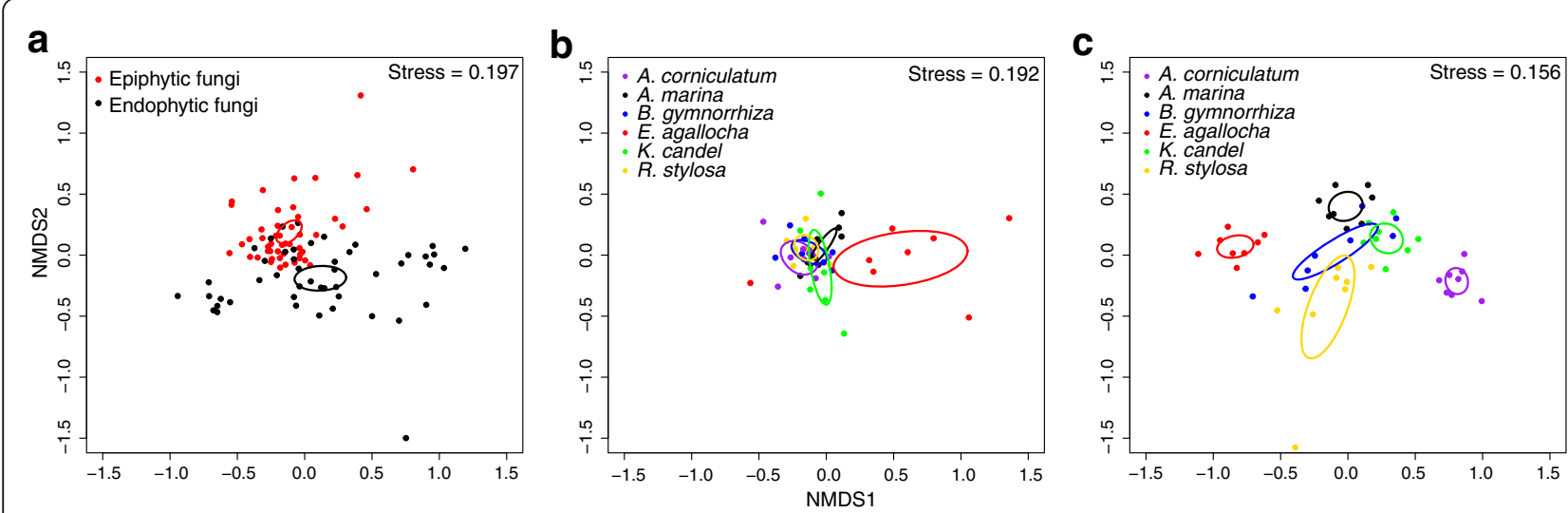

Fig. 4 Non-metric multidimensional scaling (NMDS) ordination of the community composition of epiphytic and endophytic fungi in mangrove species. a Epiphytic and endophytic fungi. b Epiphytic fungi. c Endophytic fungi. Ellipses in the plots denote $95 \%$ confidence intervals for the centroids of epiphytic and endophytic fungi (a) and different mangrove species (b, c). A. corniculatum, Aegiceras corniculatum; A. marina, Avicennia marina; B. gymnorrhiza, Bruguiera gymnorrhiza; E. agallocha, Excoecaria agallocha; K. candel, Kandelia candel; R. stylosa, Rhizophora stylosa

observed values of $H_{2}{ }^{\prime}$ and modularity were significantly higher than expected based on null models (Fig. 6c, d), whereas the observed values of weighted connectance and weighted nestedness metric based on overlap and decreasing fill (WNODF) were significantly lower than expected based on null models (Fig. 6e, f). The checkerboard scores analysis showed that the observed values for plant and fungal communities were significantly higher than those expected based on null models in both epiphytic and endophytic networks (Fig. 6g, h), indicating the existence of competitive interaction within the plant and fungal communities. Furthermore, the $Z$-score normalization analysis showed that the endophytic network was more highly specialized and more modular but less connected and more strongly anti-nested than the epiphytic network, and the degree of competitiveness within plant and fungal communities were greater in the endophytic network than in the epiphytic network (Fig. 6i).

\section{Discussion}

This study showed that Ascomycota and Basidiomycota were relatively abundant in both epiphytic and endophytic fungal communities, which is in accordance with the findings of some previous studies using cultureindependent methods [21, 47, 48]. However, previous studies using culture-based methods revealed that Ascomycota but not Basidiomycota were dominant in epiphytic and endophytic fungal communities [3, 23, 49, 50]. This difference may be ascribed to study methodology, as there are multiple challenges that limit the detection of Basidiomycota using traditional culture-based approaches [51]. For example, some Basidiomycota do not grow, or grow slowly, in culture in comparison to most Ascomycota and they are easily out-competed during the culturing process $[3,52,53]$. By contrast, culture-independent methods, such as high-throughput DNA sequencing techniques, can give a more complete picture of fungal communities compared with culturebased methods [47, 48, 51, 54]. We also found that Dothideomycetes and Tremellomycetes were dominant in epiphytic and endophytic fungal communities. In other studies, members of these fungal classes were also reported to be abundant in epiphytic $[20,48]$ and endophytic $[47,54,55]$ fungal communities.

We found that plant identity had a significant effect on the OTU richness of endophytic fungi, but not on that of epiphytic fungi. Similarly, some previous studies have revealed that plant identity significantly influences the richness of endophytic fungi [14, 18], but not that of epiphytic fungi [20]. This difference may be because although different plant species receive the same fungal propagules on the leaf surface, endophytic fungi are filtered more by host plants than are epiphytic fungi [13]. For example, endophytic fungi need to penetrate host surfaces and absorb nutrients from hosts, and different plant species have various foliar physical characters and nutrient contents which can affect endophytic fungal colonization $[17,56]$. By contrast, epiphytic fungi depend on nutrients deposited on leaves from the atmosphere or those exuded from leaves and are likely to be more affected by external environmental factors, such as wind speed, temperature, relative humidity, and solar radiation, rather than by the hosts [22].

This study showed that the community composition of epiphytic and endophytic fungi was significantly different, as reported in previous studies [13, 20-23, 50]. This difference may be caused by the distinct leaf microenvironments where epiphytic and endophytic fungi live, as mentioned above [13, 17, 22, 56]. In fact, we found that $18.7 \%$ and $40.8 \%$ of the total OTUs were unique 


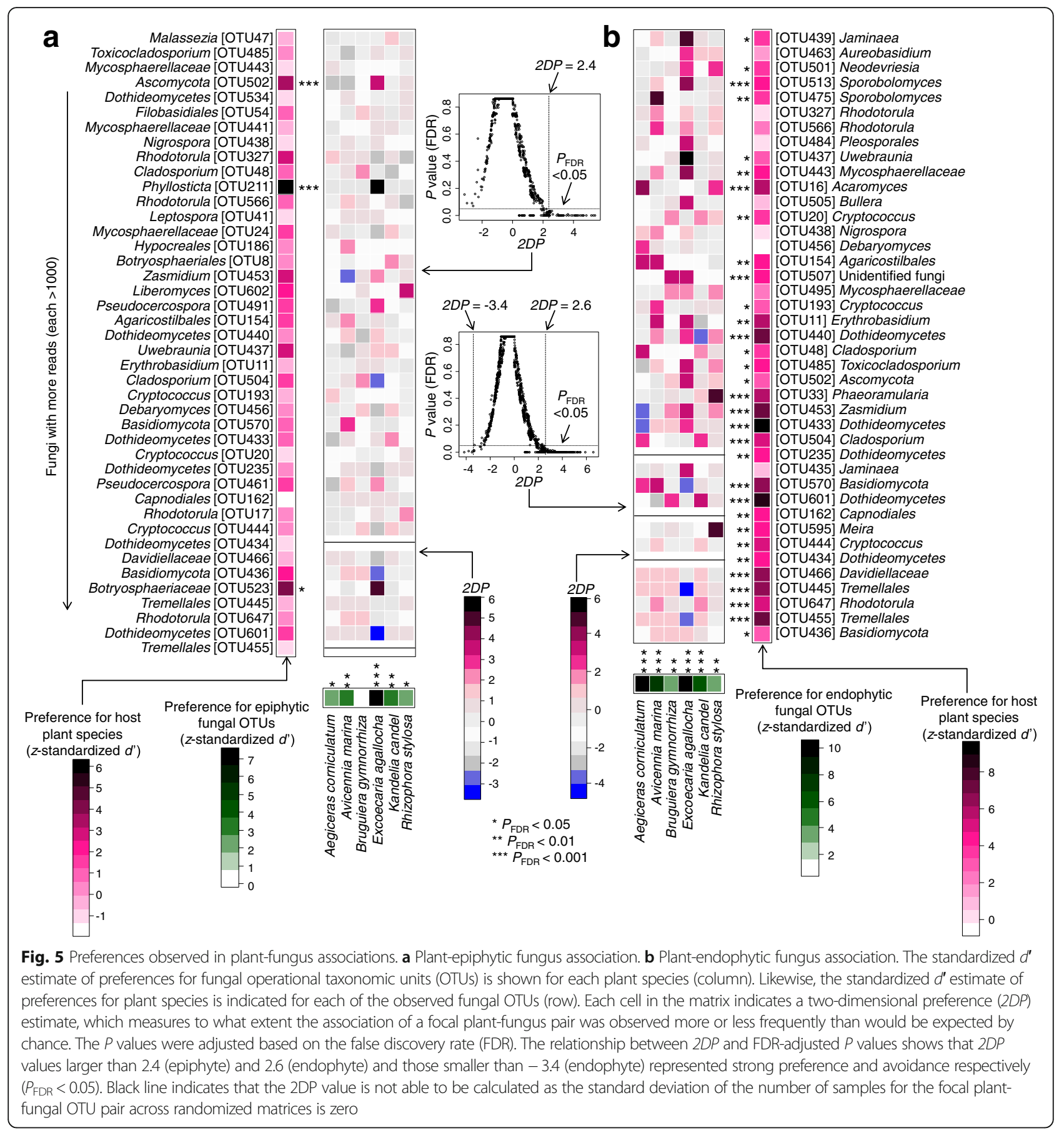

epiphytic and endophytic fungi, respectively (Additional file 2: Figure S3). For example, members of genera Curreya, Peniophora, and Cytospora were exclusively epiphytic, whereas members of genera Auriculibuller, Yamadazyma, Pseudoplectania, and Simplicillium were restricted to the role of endophytic fungi (Additional file 1: Table S1). Similarly, members of Yamadazyma, Pseudoplectania, and Simplicillium were also reported as endophytic fungi in previous studies [46, 57, 58]. In addition, some relatively abundant fungal OTUs had biased occurrence in epiphytic and endophytic fungal communities, for example, some OTUs (e.g., Rhodotorula OTU17, Phyllosticta OTU211, and Dothideomycetes OTU601) were significantly relatively more abundant in epiphytic fungi than in endophytic fungi, while some OTUs (e.g., Jaminaea OTU439, Neodevriesia OTU501, and Ascomycota OTU502) were significantly relatively more abundant in endophytic fungi than in epiphytic fungi in this study. 


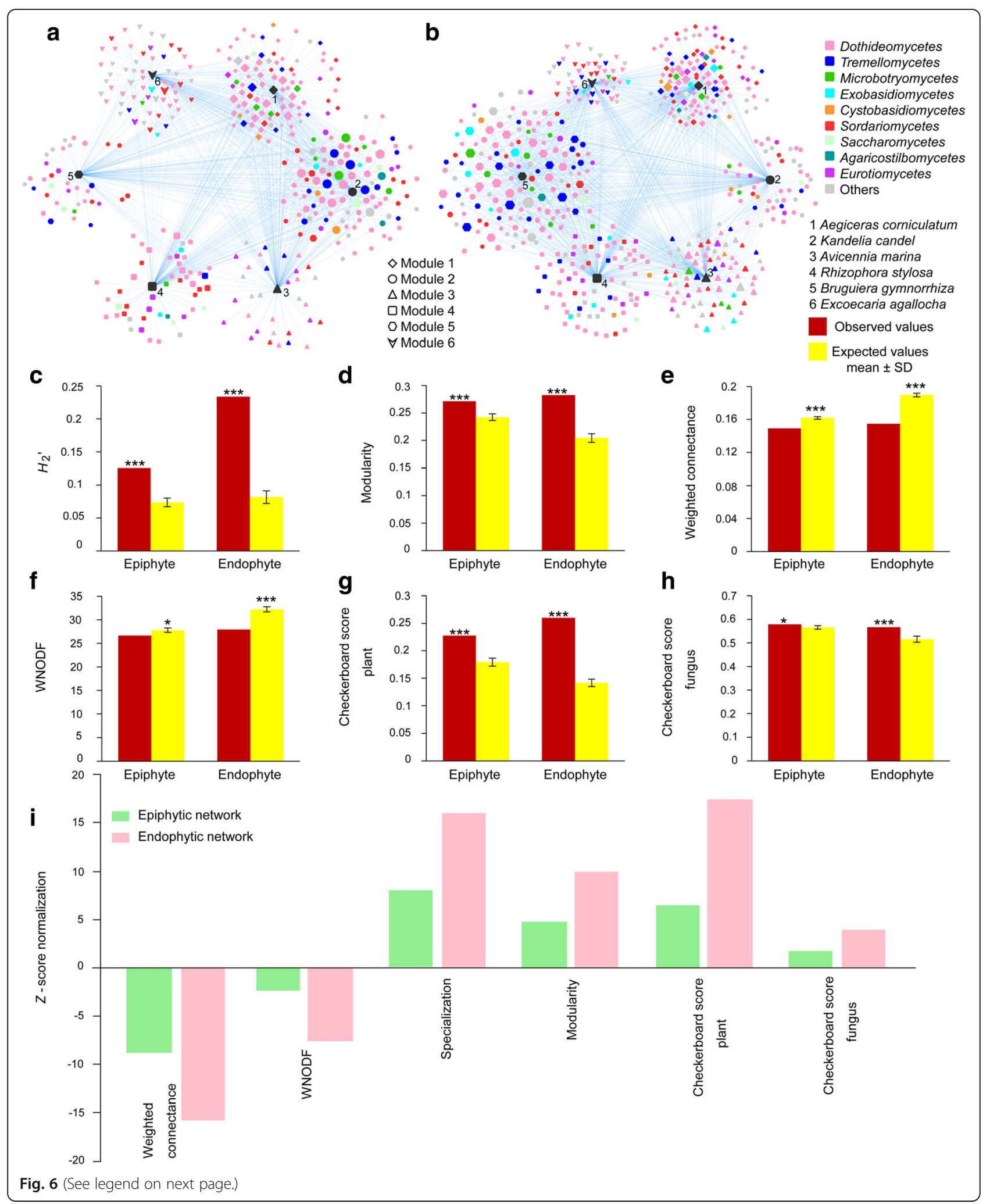


(See figure on previous page.)

Fig. 6 Architecture of the plant-fungus network. a Visualization of the epiphytic network. $\mathbf{b}$ Visualization of the endophytic network. In $\mathbf{a}$, $\mathbf{b}$, the size of nodes roughly represents the relative abundance of fungal operational taxonomic units. $\mathbf{c} \mathrm{H}_{2}^{\prime}$ metric of the network-level interaction specialization. $\mathbf{d}$ Barber's metric of modularity. e Weighted connectance. $\mathbf{f}$ Weighted nestedness metric based on overlap and decreasing fill (WNODF). $\mathbf{g}$ Checkerboard scores representing the extent to which the overlap of fungi is avoided in the plant community. $\mathbf{h}$ Checkerboard scores representing the extent to which the overlap of plants is avoided in the fungal community. i Standardized network properties with Z-score normalization of epiphytic and endophytic networks. Asterisks indicates significant differences between the observed and expected values according to $t$ test ${ }^{*} P<0.05$; $\left.{ }^{* * *} P<0.001\right)$

We found that plant identity significantly affected the community composition of both epiphytic and endophytic fungi, as reported in some previous studies [14$18,21]$. Furthermore, plant identity had a greater effect on the community composition of endophytic fungi than that of epiphytic fungi in this study. One possible explanation may be that endophytic fungi are filtered more by host plants, whereas epiphytic fungi are more affected by environmental factors as mentioned above [13, 17, $22,56]$. In addition, our findings may be due to differences in host/fungus preferences, as our host/fungus preference analysis demonstrated that more endophytic fungal OTUs showed significant preferences for hosts than did epiphytic fungal OTUs (32 vs. 3), and more host species (6 vs. 5) showed significant preferences for endophytic fungi than for epiphytic fungi. In addition, more pairs of plant species and endophytic fungi than that of plant species and epiphytic fungi (23 vs. 8) showed significantly strong preferences. Moreover, our checkerboard scores analysis indicated that negative species interaction was stronger in endophytic than in epiphytic fungal communities, as competitive interaction can affect the fungal community assembly process, in that the presence of early-arriving fungal species has a negative influence on the ability of later-arriving species to colonize hosts [59].

Network analysis showed that both epiphytic and endophytic networks were characterized by high specialization and modularity, but low connectance and anti-nestedness. This pattern is similar with plant-endophytic fungus [41], orchid-mycorrhizal fungus $[35,36]$, ericaceous plant-fungus [40], and some plant-ectomycorrhizal fungus [32, 39] networks. Furthermore, the observed values of modularity and/or specialization were lower but that of nestedness was higher in epiphytic and endophytic networks than in ericaceous plant-fungus, orchid-mycorrhizal fungus, and some plant-ectomycorrhizal fungus networks [31, 32, 35, 36, 39, 40]. However, this pattern of epiphytic and endophytic networks differs from those of plant-arbuscular mycorrhizal fungus networks, which often tend to be highly nested and lowly specialized [33, 34, 37]. In addition, the observed values of connectance and nestedness were generally lower in epiphytic and endophytic networks than in plantarbuscular mycorrhizal fungus networks [34, 39]. This difference may be ascribed to the varying degrees of connectance and specialization in different types of networks, as generally in biotrophic plant-fungal associations, nestedness increases but modularity decreases with increasing connectance [31], whereas nestedness decreases but modularity increases with increasing specificity [25].

Furthermore, we found that the endophytic network was more highly specialized and modular but less connected and more strongly anti-nested than the epiphytic network. The more strongly anti-nested pattern observed in the endophytic network compared to the epiphytic network indicates that partner-specific plant species are less likely to favor generalists over specialists among endophytic fungi than among epiphytic fungi [31]. Similarly, the higher degree of specialization and modularity in the endophytic network than in the epiphytic network suggests that plant hosts may select more strongly for a specific subset of endophytic partners than for a subset of epiphytic partners [42]. In addition, because modular organization can buffer communities against secondary extinctions following disturbance and increase overall network stability [30], the higher modularity of the endophytic network than that of the epiphytic network may suggest that the endophytic fungal community is more resistant to secondary species extinctions brought about by disturbance than is the epiphytic fungal community. In addition, we should realize that the sampling numbers in the present study are limited, which may not be enough for strong statistical analysis [60]. Therefore, more samples should be used in future study.

\section{Conclusion}

This study provides the first example of research revealing differences in community and network structures of phyllosphere epiphytic and endophytic fungi associated with mangrove species using high-throughput DNA sequencing techniques. Plant identity had greater effects on the diversity and community composition of endophytic fungi than that of epiphytic fungi. Network analysis showed the endophytic network was more highly specialized and modular but less connected and more strongly anti-nested than epiphytic network. Our findings support a more intimate relationship between plants and endophytic fungi than between plants and epiphytic fungi, and suggest that the endophytic fungal community is more resistant to environmental disturbance than the epiphytic fungal community in the 
mangrove forest ecosystem. This study may help us to deeper understand mechanisms underlying species coexistence and community stability in ecosystems.

\section{Methods}

\section{Study site and sampling}

The study was conducted in the Zhanjiang Mangrove National Nature Reserve in south China $\left(21^{\circ} 32^{\prime} \mathrm{N}, 109^{\circ}\right.$ $46^{\prime} \mathrm{E}, 20,278.8 \mathrm{ha}, 2-7 \mathrm{~m}$ above sea level). This study site is located in a tropical climate zone, with an annual mean temperature of $23.4{ }^{\circ} \mathrm{C}$, and an annual mean precipitation of $1600 \mathrm{~mm}$, occurring mostly from April to September. There are six mangrove species, Aegiceras corniculatum (Myrsinaceae), Avicennia marina (Verbenaceae), Bruguiera gymnorrhiza, Kandelia candel and Rhizophora stylosa (Rhizophoraceae), and Excoecaria agallocha (Euphorbiaceae), at the site. On 15 March 2015, we selected eight individuals (replicates) of each of the six plant species, each $>50 \mathrm{~m}$ away from all other members of the same plant species. Subsequently, 30 healthy leaves were randomly collected from each plant individual, and immediately placed in sterile plastic bags, labeled, and transported to laboratory in an ice-box. In total, 48 leaf samples were used in this study. All the samples were stored at $-80{ }^{\circ} \mathrm{C}$ until required for DNA extraction.

\section{Molecular analysis}

Epiphytic fungi were washed from leaf surfaces according to Gourion et al. [61]. Frozen leaves $(5.0 \mathrm{~g})$ were transferred into a $50-\mathrm{mL}$ plastic tube filled with sterile cooled TE buffer (10 mM Tris-HCl, $1 \mathrm{mM}$ EDTA, $\mathrm{pH}$ 7.5) and then subjected to alternating sonication (45 s) and vortexing (30 s) three times. The leaves were transferred to new tubes and the suspension was centrifuged at $10,000 \times g$ for $10 \mathrm{~min}$. The supernatant was discarded, then the pellet was resuspended in $5 \mathrm{~mL}$ cetyltrimethylammonium bromide (CTAB) extraction buffer $(2 \%(w /$ v) $\mathrm{CTAB}, 100 \mathrm{mM}$ Tris-HCl, $1.4 \mathrm{M} \mathrm{NaCl}, 20 \mathrm{mM}$ EDTA, 1.5\% PVP, 0.5\% 2-mercaptoethanol, pH 8.0) preheated to $65{ }^{\circ} \mathrm{C}$, and homogenized at $6.0 \mathrm{~m} / \mathrm{s}$ for $30 \mathrm{~s}$ in a FastPrep-24 Instrument (MP Biomedicals, Illkirch, France) according to the manufacturer's instructions. For endophytic fungi, the leaf samples described above were surface sterilized by consecutive immersion for $1 \mathrm{~min}$ in $75 \%$ ethanol, $3 \mathrm{~min}$ in $3.25 \%$ sodium hypochlorite, and $30 \mathrm{~s}$ in $75 \%$ ethanol, followed by three rinses in sterile distilled water [49]. Subsequently, the treated leaves were freeze-dried using liquid nitrogen and homogenized using a sterilized mortar and pestle and then transferred to a tube with $5 \mathrm{~mL}$ CTAB extraction buffer preheated to $65{ }^{\circ} \mathrm{C}$. Genomic DNA of epiphytic and endophytic fungi was extracted using the modified CTAB method [49]. The DNA concentration was measured using a NanoDrop 1000 Spectrophotometer (Thermo Scientific, Wilmington, USA).

The fungal internal transcribed spacer 2 (ITS2) region of rRNA gene was amplified for high-throughput Illumina MiSeq sequencing using a two-step PCR procedure. The initial amplification of the entire ITS region with primers ITS1F [62] and ITS4 [63] was carried out in a $25 \mu \mathrm{L}$ reaction solution containing $2.5 \mu \mathrm{L} 10 \times$ buffer, $1.5 \mathrm{mM} \mathrm{MgSO}_{4}, 250 \mu \mathrm{M}$ of each dNTP, $0.75 \mu \mathrm{M}$ of each primer, 0.5 U KOD-plus-Neo polymerase (Toyobo, Tokyo, Japan), and $10 \mathrm{ng}$ of template DNA. The PCR conditions were set at $94{ }^{\circ} \mathrm{C}$ for $5 \mathrm{~min}, 30$ cycles for denaturation at $94{ }^{\circ} \mathrm{C}$ for $1 \mathrm{~min}$, annealing at $54{ }^{\circ} \mathrm{C}$ for $50 \mathrm{~s}$, and extension at $68{ }^{\circ} \mathrm{C}$ for $1 \mathrm{~min}$, followed by a final extension at $68{ }^{\circ} \mathrm{C}$ for $10 \mathrm{~min}$. The product of the first PCR was diluted by a factor of 50 with sterile deionized water and $1.0 \mu \mathrm{L}$ of the diluted solution was used as a template for the second PCR with the same conditions as the first amplification, except that the primers used were fITS7 [64] and ITS4 linked with 12-base barcode sequences. Furthermore, the sterile water used in the final rinse was subjected to the two-step PCR as negative controls to test the efficacy of surface sterilization. No PCR products were detected demonstrating the effectiveness of the surface sterilization procedure. We also used sterile deionized distilled water as negative controls in all steps of the PCR procedure to test the presence of contamination in reagents. No bands were observed in all negative controls. The PCR products were purified using a PCR Product Gel Purification Kit (Bioteke, Beijing, China), and $50 \mathrm{ng}$ purified DNA of each of the 96 samples was pooled and adjusted to $10 \mathrm{ng} \mu \mathrm{L}^{-1}$. A sequencing library was generated by addition of an Illumina sequencing adaptor (5'-GATCGGAAGAGCAC ACGTCTGAACTCCAGTCACATCACGATCTCGTAT GCCGTCTTCTGCTTG-3') to the product using an Illumina TruSeq DNA PCR-Free Library Preparation Kit (Illumina, CA, USA), following the manufacturer's instructions. The library was applied to an Illumina MiSeq PE 250 platform for sequencing using the paired end option $(2 \times 250$ base pairs (bp) $)$ at the Environmental Genome Platform of Chengdu Institute of Biology, Chinese Academy of Sciences, China.

\section{Bioinformatics analysis}

Raw sequences were filtered using Quantitative Insights into Microbial Ecology (QIIME) version 1.7.0 [65] to eliminated low-quality sequences, defined as those with an average quality score $<20$, without valid primer sequence or barcode sequence, containing ambiguous bases, or length $<250 \mathrm{bp}$. Of the remaining sequences, the ITS2 region was extracted using the fungal ITSx software package [66], and potential chimeras were subsequently checked using the chimera.uchime command 
in MOTHUR version 1.31.2 [67] by comparison to entries in the unified system for the DNA based fungal species linked to the classification (UNITE) database [68]. The non-chimeric sequences were clustered into operational taxonomic units (OTUs) at a 97\% sequence similarity level based on the UPARSE pipeline using USEARCH version 8.0 [69] after dereplication and discarding all singletons. A representative sequence (the most abundant) of each OTU was selected for searching against the UNITE database version 18.11.2018 [70] using the sintax function [71] in USEARCH with a confidence cut-off $(P)$ value of 0.65 . We then excluded the OTUs with $<10$ reads from all the samples as their sequences could contain PCR or sequencing errors [72]. To eliminate the effects of different sequence numbers among the samples on the fungal community identified, the number of sequences per sample was normalized to the smallest sample size using the sub.sample command in MOTHUR. The representative fungal OTU sequences have been submitted to the European Nucleotide Archive (ENA) under study accession number PRJEB24460. Detailed information about fungi in the present study is given in Additional file 1: Table S1.

\section{Data analysis}

All the statistical analyses were implemented in $R$ version 3.3.2 [73], except for the network visualization, which was carried out in CYTOSCAPE version 3.4.0 [74], and modularity analysis, which used the program MODULAR [75]. Fungal OTU richness is defined as the number of fungal OTUs in a sample. The relative abundance of a specific fungal OTU and class is defined as the number of reads of that OTU and class as a percentage of the number of all reads in a sample. One-way analysis of variance (ANOVA) was used to explore the effect of plant identity on fungal OTU richness after the square root or log transformation as the data did not satisfy the normality of distribution and homogeneity of variance, then significant differences between plant species were further compared using Tukey's honestly significant difference (HSD) test at $P<0.05$. As the data of endophytic fungal OTU richness did not satisfy the normality of distribution and homogeneity of variance after the square root and $\log$ transformation, then nonparametric Kruskal-Wallis test was used, followed by Conover's test for multiple comparisons using the posthoc.kruskal.conover.test function in the PMCMR package [76]. The relative abundances of abundant epiphytic and endophytic fungal OTUs (> 1000 reads) among different plant species were depicted using the pheatmap function in the pheatmap package version 1.0.8 [77]. Furthermore, the relative abundance of abundant OTUs between the epiphytic and endophytic fungi in each plant species was compared using paired $t$ test if the data satisfy the normality of distribution after the root square or log transformation; otherwise, paired Wilcoxon signed rank test was used. In addition, we conducted indicator species analysis of fungal OTUs for each plant species based on the OTU relative abundance (indval value $>0.6$ and $P<0.05$ are strong indicators for a species) using the indval function in the labdsv package version 1.8-0 [78].

The distance matrices of community composition (Hellinger-transformation of the OTU read data) of epiphytic and endophytic fungi were constructed by calculating dissimilarities using the Bray-Curtis method [79]. Subsequently, non-metric multidimensional scaling (NMDS) was used to visualize the community composition dissimilarities of epiphytic and endophytic fungi using the metaMDS command in the vegan package version 2.4-1 [80]. In order to evaluate the effect of plant identity on the community composition of epiphytic and endophytic fungi, permutational multivariate analysis of variance (PerMANOVA) was carried out, using the adonis command in the vegan package, based on 999 permutations [80]. The rarefaction curves of the OTUs of epiphytic and endophytic fungi observed in each plant species were calculated using the specaccum function in the vegan package [80].

Host/fungus preference analysis was carried out according to Toju et al. [40]. In brief, the sample (row) $\times$ fungal OTU (column) data matrix (in which a cell entry depicts the number of reads of an OTU in a sample) was binarized to a sample-level matrix (present-absent data) and then converted into a species-level matrix (quantitative data), in which rows denote plant species, columns represent fungal OTUs, and cell entries indicate the number of samples from which respective combinations of plants and fungi were observed. By shuffling the plant species labels in the sample $\times$ fungal OTU matrix, a randomized species-level matrix was obtained based on 1000 permutations. The interaction specialization index $\left(d^{\prime}\right)$ [81] was calculated using the dfun function in the bipartite 2.05 package [82]. The $d^{\prime}$ value of each fungal OTU was standardized as follows: standardized $d^{\prime}=\left[d^{\prime}\right.$ observed - Mean $\left(d^{\prime}\right.$ randomized $\left.)\right] / \mathrm{SD}$ $\left(d^{\prime}\right.$ randomized $)$, where $d^{\prime}$ observed is the $d^{\prime}$ estimate of the original data, and Mean ( $d^{\prime}$ randomized $)$ and SD ( $d^{\prime}$ randomized $)$ are the mean and standard deviation of the $d^{\prime}$ values of the randomized data matrices. The standardized $d^{\prime}$ of each plant species was also calculated based on the original and randomized data matrices as mentioned above. Because it is difficult to estimate the host preferences of rare fungi, the $d$ ' estimates of the relatively abundant epiphytic and endophytic fungal OTUs ( $>1000$ reads) in the sample $\times$ fungal OTU matrix are shown. In addition, based on the species-level original and randomized matrices, we quantified two-dimensional preferences $(2 D P)$ to evaluate to what extent each pair of a plant species $(i)$ and fungal OTU $(j)$ was observed (counts) more or less frequently than would 
be expected by chance. $2 D P(i, j)=\left[N_{\text {observed }}(i, j)\right.$ - Mean $\left.\left(N_{\text {randomized }}(i, j)\right)\right] /$ SD $\left(N_{\text {randomized }}(i, j)\right)$, where $N_{\text {observed }}(i$, $j$ ) is the number of the samples from which a pair of a plant species and a fungal OTU was observed in the original data, and Mean $\left(N_{\text {randomized }}(i, j)\right)$ and SD $\left(N_{\text {randomized }}(i, j)\right)$ are the mean and the standard deviation of the number of samples for the focal plant-fungal OTU pair across randomized matrices. The $P$ value obtained from the preference analysis was adjusted based on the false discovery rate (FDR) [83].

To visualize network structure for the epiphytic and endophytic fungi, we drew a network based on the species-level matrices using the prefuse force directed opencl layout in CYTOSCAPE version 3.4.0 [74]. We then examined the architectural properties of the epiphytic and endophytic networks based on the species-level matrices according to Toju et al. [40]. To perform a randomization test, randomized matrices were obtained based on the shuffle-sample null model with 1000 permutations. The network indices used in the analysis were the weighted connectance [84], the $H_{2}{ }^{\prime}$ metric of network-level specialization [81], Barber's metric of bipartite network modularity [85], the weighted nestedness metric based on overlap and decreasing fill (WNODF) [86], and checkerboard scores [87] representing the degree to which overlap of partners was avoided within the plant/ fungus community. Calculations of the weighted connectance, $H_{2}{ }^{\prime}$, WNODF, and checkerboard scores were performed based on the species-level original and randomized matrices using the networklevel command in the bipartite package [82]. For modularity analysis, the species-level original and randomized matrices were binarized and output from R. Subsequently, the binary data were analyzed in the MODULAR program for simulated annealing-based estimation of network modularity [88]. Next, $t$ tests were used to examine the difference between the observed and the random values at $P<0.05$. To make comparisons across networks, the network indices were standardized with $Z$-score normalization which can correct for variation in species richness and the number of interactions [89]. The $Z$-score is defined as $Z=\left(E_{\text {observed }}-E_{\text {randomized }}\right) / \mathrm{SD}_{\text {rando- }}$ mized, where $E_{\text {observed }}$ is the observed value and $E_{\text {randomized }}$ and $\mathrm{SD}_{\text {randomized }}$ are the mean value and the standard deviation of the randomized matrices [89].

\section{Additional files}

Additional file 1: Table S1. Molecular identification of epiphytic and endophytic fungi at a 97\% sequence identity level in this study. (XLSX $113 \mathrm{~kb}$ )

Additional file 2: Figure S1. Ranking by abundance of the observed fungal operational taxonomic units (OTUs). a Epiphytic fungi. b Endophytic fungi. Figure S2. Rarefaction curves for the observed fungal operational taxonomic units (OTUs) in mangrove species. a Epiphytic fungi. b Endophytic fungi. A. corniculatum, Aegiceras corniculatum; A. marina, Avicennia marina; B. gymnorrhiza, Bruguiera gymnorrhiza; E. agallocha, Excoecaria agallocha; K. candel, Kandelia candel; R. stylosa Rhizophora stylosa. Figure S3. Venn diagram showing the number of specific and shared operational taxonomic units (OTUs) of epiphytic and endophytic fungi. The percentage of these OTUs accounting for the total number of OTUs shows in parenthesis. (DOCX $127 \mathrm{~kb}$ )

Additional file 3: Table S2. Comparison of the relative abundance of abundant operational taxonomic units (OTUs, $>1000$ reads) between epiphytic and endophytic fungi. (XLSX $16 \mathrm{~kb}$ )

\section{Acknowledgements}

We are grateful to staff of the Zhanjiang Mangrove National Nature Reserve for sample collection and identifying plant species. We thank Prof. Ian C Anderson for his valuable suggestions on the organization of this paper.

\section{Funding}

This work was financially supported by the Strategic Priority Research Program of the Chinese Academy of Sciences (XDB31000000), the Special Project for Basic Work in Science and Technology of China (No. 2013FY111200), the National Natural Science Foundation of China (No. 31470151), and the Biological Resources Service Network Initiative of the Chinese Academy of Sciences (No. ZSSD-015).

Availability of data and materials

Representative sequences of the fungal OTUs at the $97 \%$ sequence identity level have been submitted to the European Nucleotide Archive (ENA) under study accession number PRJEB24460.

\section{Authors' contributions}

LDG designed the experiment; CH and LDG collected the samples; XS, XCL, and PM performed the laboratory work; and HY and LDG analyzed the data and wrote the manuscript. All authors read and approved the final manuscript.

Ethics approval and consent to participate

Not applicable.

Consent for publication

Not applicable.

\section{Competing interests}

The authors declare that they have no competing interests.

\section{Publisher's Note}

Springer Nature remains neutral with regard to jurisdictional claims in published maps and institutional affiliations.

\section{Author details}

${ }^{1}$ State Key Laboratory of Mycology, Institute of Microbiology, Chinese Academy of Sciences, Beijing 100101, People's Republic of China. ${ }^{2}$ College of Life Sciences, University of Chinese Academy of Sciences, Beijing 100049, People's Republic of China. ${ }^{3}$ Institute of Medicinal Plant Development, Chinese Academy of Medical Sciences and Peking Union Medical College, Beijing 100193, People's Republic of China.

Received: 23 October 2018 Accepted: 22 March 2019 Published online: 09 April 2019

\section{References}

1. Wardle DA, Bardgett RD, Klironomos JN, Setälä H, van der Putten WH, Wall $\mathrm{DH}$. Ecological linkages between aboveground and belowground biota. Science. 2004;304:1629-33. https://doi.org/10.1126/science.1094875

2. Arnold AE, Mejía LC, Kyllo D, Rojas El, Maynard Z, Robbins N, et al. Fungal endophytes limit pathogen damage in a tropical tree. Proc Natl Acad Sci U S A. 2003;100:15649-54. https://doi.org/10.1073/pnas.2533483100

3. Arnold AE, Henk DA, Eells RL, Lutzoni F, Vilgalys R. Diversity and phylogenetic affinities of foliar fungal endophytes in loblolly pine inferred by culturing and environmental PCR. Mycologia. 2007;99:185-206. https:// doi.org/10.1080/15572536.2007.11832578 
4. Guerreiro MA, Brachmann A, Begerow D, Peršoh D. Transient leaf endophytes are the most active fungi in 1-year-old beech leaf litter. Fungal Divers. 2018:89:237-51. https://doi.org/10.1007/s13225-017-0390-4

5. Jumpponen A, Jones KL. Massively parallel 454 sequencing indicates hyperdiverse fungal communities in temperate Quercus macrocarpa phyllosphere. New Phytol. 2009;184:438-48. https://doi.org/10.1111/j.14698137.2009.02990.x

6. Kannadan S, Rudgers JA. Endophyte symbiosis benefits a rare grass under Iow water availability. Funct Ecol. 2008;22:706-13. https://doi.org/10.1111/j. 1365-2435.2008.01395.x

7. Waller F, Achatz B, Baltruschat H, Fodor J, Becker K, Fischer M, et al. The endophytic fungus Piriformospora indica reprograms barley to salt-stress tolerance, disease resistance, and higher yield. Proc Natl Acad Sci U S A. 2005; 102:13386-91. https://doi.org/10.1073/pnas.0504423102

8. Purahong $W$, Hyde KD. Effects of fungal endophytes on grass and non-grass litter decomposition rates. Fungal Divers. 2011;47:1-7. https://doi.org/10. 1007/s13225-010-0083-8

9. Sun X, Guo LD, Hyde KD. Community composition of endophytic fungi in Acer truncatum and their role in decomposition. Fungal Divers. 2011;47:8595. https://doi.org/10.1007/s13225-010-0086-5

10. Voříšková J, Baldrian P. Fungal community on decomposing leaf litter undergoes rapid successional changes. ISME J. 2013;7:477-86. https://doi. org/10.1038/ismej.2012.116

11. Inácio J, Pereira P, de Carvalho M, Fonseca Á, Amaral-Collaço MT, SpencerMartins I. Estimation and diversity of phylloplane mycobiota on selected plants in a Mediterranean-type ecosystem in Portugal. Microb Ecol. 2002;44: 344-53. https://doi.org/10.1007/s00248-002-2022-z

12. Clay K, Schardl C. Evolutionary origins and ecological consequences of endophyte symbiosis with grasses. Am Nat. 2002;160:S99-S127. https://doi. org/10.1086/342161

13. Santamaria J, Bayman P. Fungal epiphytes and endophytes of coffee leaves (Coffea arabica). Microb Ecol. 2005;50:1-8. https:/doi.org/10.1007/s00248-004-0002-1

14. Lau MK, Arnold AE, Johnson NC. Factors influencing communities of foliar fungal endophytes in riparian woody plants. Fungal Ecol. 2013;6:365-78. https://doi.org/10.1016/j.funeco.2013.06.003

15. Peršoh D. Factors shaping community structure of endophytic fungievidence from the Pinus-Viscum-system. Fungal Divers. 2013;60:55-69. https://doi.org/10.1007/s13225-013-0225-x

16. Sun X, Ding Q, Hyde KD, Guo LD. Community structure and preference of endophytic fungi of three woody plants in a mixed forest. Fungal Ecol. 2012;5:624-32. https://doi.org/10.1016/j.funeco.2012.04.001

17. Vincent JB, Weiblen GD, May G. Host associations and beta diversity of fungal endophyte communities in New Guinea rainforest trees. Mol Ecol. 2016;25:825-41. https://doi.org/10.1111/mec.13510

18. Wearn JA, Sutton BC, Morley NJ, Gange AC. Species and organ specificity of fungal endophytes in herbaceous grassland plants. J Ecol. 2012;100:1085-92. https://doi.org/10.1111/j.1365-2745.2012.01997.x

19. Flessa F, Peršoh D, Rambold G. Annuality of central European deciduous tree leaves delimits community development of epifoliar pigmented fungi. Fungal Ecol. 2012;5:554-61. https://doi.org/10.1016/j.funeco.2011.12.005

20. Fonseca-García C, Coleman-Derr D, Garrido E, Visel A, Tringe SG, Partida-Martínez LP. The cacti microbiome: interplay between habitat-filtering and hostspecificity. Front Microbiol. 2016;7(150) https:/doi.org/10.3389/fmicb.2016.00150

21. Coleman-Derr D, Desgarennes D, Fonseca-Garcia C, Gross S, Clingenpeel S, Woyke T, et al. Plant compartment and biogeography affect microbiome composition in cultivated and native Agave species. New Phytol. 2016;209: 798-811. https://doi.org/10.1111/nph.13697

22. Gomes T, Pereira JA, Benhadi J, Lino-Neto T, Baptista P. Endophytic and epiphytic phyllosphere fungal communities are shaped by different environmental factors in a Mediterranean ecosystem. Microb Ecol. 2018;76:66879. https:/doi.org/10.1007/s00248-018-1161-9

23. Osono T. Endophytic and epiphytic phyllosphere fungi of red-osier dogwood (Cornus stolonifera) in British Columbia. Mycoscience. 2007:48:4752. https://doi.org/10.1007/s10267-006-0329-1

24. Montesinos-Navarro A, Segarra-Moragues JG, Valiente-Banuet A, Verdú M. Plant facilitation occurs between species differing in their associated arbuscular mycorrhizal fungi. New Phytol. 2012;196:835-44. https:/doi.org/10.1111/j.14698137.2012.04290x

25. van der Heijden MGA, Martin FM, Selosse MA, Sanders IR. Mycorrhizal ecology and evolution: the past, the present, and the future. New Phytol. 2015;205:1406-23. https://doi.org/10.1111/nph.13288
26. Bascompte J, Jordano P, Melián CJ, Olesen JM. The nested assembly of plant-animal mutualistic networks. Proc Natl Acad Sci U S A. 2003;100:93837. https://doi.org/10.1073/pnas.1633576100

27. Olesen JM, Bascompte J, Dupont $\mathrm{YL}$, Jordano P. The modularity of pollination networks. Proc Natl Acad Sci U S A. 2007;104:19891-6. https:// doi.org/10.1073/pnas.0706375104

28. Burgos E, Ceva H, Perazzo RPJ, Devoto M, Medan D, Zimmermann M, et al. Why nestedness in mutualistic networks? J Theor Biol. 2007;249:307-13. https://doi.org/10.1016/j.jtbi.2007.07.030

29. Bastolla U, Fortuna MA, Pascual-García A, Ferrera A, Luque B, Bascompte J. The architecture of mutualistic networks minimizes competition and increases biodiversity. Nature. 2009;458:1018-20. https:/doi.org/10.1038/nature07950

30. Stouffer DB, Bascompte J. Compartmentalization increases food-web persistence. Proc Natl Acad Sci U S A. 2011;108:3648-52. https://doi.org/10. 1073/pnas.1014353108

31. Põlme S, Bahram M, Jacquemyn H, Kennedy $P$, Kohout $P$, Moora M, et al. Host preference and network properties in biotrophic plant-fungal associations. New Phytol. 2018;217:1230-9. https://doi.org/10.1111/nph.14895

32. Bahram M, Harend $H$, Tedersoo L. Network perspectives of ectomycorrhizal associations. Fungal Ecol. 2014;7:70-7. https://doi.org/10.1016/j.funeco.2013.10.003

33. Chagnon PL, Bradley RL, Klironomos JN. Using ecological network theory to evaluate the causes and consequences of arbuscular mycorrhizal community structure. New Phytol. 2012;194:307-12. https://doi.org/10.1111/ j.1469-8137.2011.04044.X

34. Chen L, Zheng Y, Gao C, Mi XC, Ma KP, Wubet T, et al. Phylogenetic relatedness explains highly interconnected and nested symbiotic networks of woody plants and arbuscular mycorrhizal fungi in a Chinese subtropical forest. Mol Ecol. 2017;26:2563-75. https://doi.org/10.1111/mec.14061

35. Jacquemyn $H$, Brys R, Waud M, Busschaert P, Lievens B. Mycorrhizal networks and coexistence in species-rich orchid communities. New Phytol. 2015;206:1127-34. https://doi.org/10.1111/nph.13281

36. Martos F, Munoz F, Pailler T, Kottke I, Gonneau C, Selosse MA. The role of epiphytism in architecture and evolutionary constraint within mycorrhizal networks of tropical orchids. Mol Ecol. 2012;21:5098-109. https://doi.org/10. 1111/j.1365-294X.2012.05692.x

37. Montesinos-Navarro A, Segarra-Moragues JG, Valiente-Banuet A, Verdú M. The network structure of plant-arbuscular mycorrhizal fungi. New Phytol. 2012;194:536-47. https://doi.org/10.1111/j.1469-8137.2011.04045.x

38. Toju H, Guimarães PR, Olesen JM, Thompson JN. Assembly of complex plant-fungus networks. Nat Commun. 2014;5(5273) https://doi.org/10.1038/ ncomms6273

39. Toju H, Guimarães PR, Olesen JM, Thompson JN. Below-ground plantfungus network topology is not congruent with above-ground plant-animal network topology. Sci Adv. 2015;1:e1500291. https://doi.org/10.1126/sciadv. 1500291

40. Toju H, Tanabe AS, Ishii HS. Ericaceous plant-fungus network in a harsh alpine-subalpine environment. Mol Ecol. 2016;25:3242-57. https://doi.org/10, 1111/mec.13680

41. Ikeda A, Matsuoka S, Masuya H, Mori AS, Hirose D, Osono T. Comparison of the diversity, composition, and host recurrence of xylariaceous endophytes in subtropical, cool temperate, and subboreal regions in Japan. Popul Ecol. 2014;56:289-300. https://doi.org/10.1007/s10144-013-0412-3

42. Chagnon PL, U'Ren JM, Miadlikowska J, Lutzoni F, Arnold AE. Interaction type influences ecological network structure more than local abiotic conditions: evidence from endophytic and endolichenic fungi at a continental scale. Oecologia. 2016;180:181-91. https://doi.org/10.1007/ s00442-015-3457-5

43. Guimarães PR, Rico-Gray V, Oliveira PS, Izzo TJ, dos Reis SF, Thompson JN. Interaction intimacy affects structure and coevolutionary dynamics in mutualistic networks. Curr Biol. 2007;17:1797-803. https://doi.org/10.1016/j. cub.2007.09.059

44. Giri C, Ochieng E, Tieszen LL, Zhu Z, Singh A, Loveland T, et al. Status and distribution of mangrove forests of the world using earth observation satellite data. Global Ecol Biogeogr. 2011;20:154-9. https://doi.org/10.1111/j. 1466-8238.2010.00584.x

45. Kumaresan $V$, Suryanarayanan TS. Endophyte assemblages in young, mature and senescent leaves of Rhizophora apiculata: evidence for the role of endophytes in mangrove litter degradation. Fungal Divers. 2002;9:81-91.

46. Li JL, Sun X, Chen L, Guo LD. Community structure of endophytic fungi of four mangrove species in southern China. Mycology. 2016;7:180-90. https:// doi.org/10.1080/21501203.2016.1258439 
47. Bálint M, Bartha L, O'Hara RB, Olson MS, Otte J, Pfenninger M, et al. Relocation, high-latitude warming and host genetic identity shape the foliar fungal microbiome of poplars. Mol Ecol. 2015;24:235-48. https:/doi.org/10.1111/mec. 13018

48. Kembel SW, Mueller RC. Plant traits and taxonomy drive host associations in tropical phyllosphere fungal communities. Botany. 2014;92:303-11. https:// doi.org/10.1139/cjb-2013-0194

49. Guo LD, Hyde KD, Liew ECY. Identification of endophytic fungi from Livistona chinensis based on morphology and rDNA sequences. New Phytol. 2000;147: 617-30. https://doi.org/10.1046/j.1469-8137.2000.00716.x

50. Zambell CB, White JF. In the forest vine Smilax rotundifolia, fungal epiphytes show site-wide spatial correlation, while endophytes show evidence of niche partitioning. Fungal Divers. 2015;75:279-97. https://doi.org/10.1007/s13225-0140316-3

51. Sun X, Guo LD. Endophytic fungal diversity: review of traditional and molecular techniques. Mycology. 2012;3:65-76. https://doi.org/10.1080/21501203.2012. 656724

52. Guo LD, Hyde KD, Liew ECY. Detection and taxonomic placement of endophytic fungi within frond tissues of Livistona chinensis based on rDNA sequences. Mol Phylogenet Evol. 2001;20:1-13. https:/doi.org/10.1006/mpev. 2001.0942

53. Martin R, Gazis R, Skaltsas D, Chaverri P, Hibbett D. Unexpected diversity of basidiomycetous endophytes in sapwood and leaves of Hevea. Mycologia. 2015; 107:284-97. https://doi.org/10.3852/14-206

54. Dissanayake AJ, Purahong W, Wubet T, Hyde KD, Zhang W, Xu HY, et al. Direct comparison of culture-dependent and culture-independent molecular approaches reveal the diversity of fungal endophytic communities in stems of grapevine (Vitis vinifera). Fungal Divers. 2018;90:85-107. https://doi.org/10.1007/ s13225-018-0399-3

55. Higgins KL, Arnold AE, Miadlikowska J, Sarvate SD, Lutzoni F. Phylogenetic relationships, host affinity, and geographic structure of boreal and arctic endophytes from three major plant lineages. Mol Phylogenet Evol. 2007;42:54355. https://doi.org/10.1016/j.ympev.2006.07.012

56. Larkin BG, Hunt LS, Ramsey PW. Foliar nutrients shape fungal endophyte communities in Western white pine (Pinus monticola) with implications for white-tailed deer herbivory. Fungal Ecol. 2012;5:252-60. https://doi.org/10.1016/j. funeco.2011.11.002

57. Khunnamwong P, Limtong S. Yamadazyma endophytica f.a. sp. nov., an ascomycetous yeast species isolated from leaf tissue. Int J Syst Evol Microbiol. 2016;66:2717-23. https://doi.org/10.1099/ijsem.0.001113

58. Supaphon P, Phongpaichit S, Rukachaisirikul V, Sakayaroj J. Diversity and antimicrobial activity of endophytic fungi isolated from the seagrass Enhalus acoroides. Indian J Geo-Mar Sci. 2014;43:785-97.

59. Pan JJ, May G. Fungal-fungal associations affect the assembly of endophyte communities in maize (Zea mays). Microb Ecol. 2009;58:668-78. https://doi. org/10.1007/s00248-009-9543-7

60. Tkacz A, Cheema J, Chandra G, Grant A, Poole PS. Stability and succession of the rhizosphere microbiota depends upon plant type and soil composition. ISME J. 2015;9:2349-59. https://doi.org/10.1038/ismej.2015.41

61. Gourion B, Rossignol M, Vorholt JA. A proteomic study of Methylobacterium extorquens reveals a response regulator essential for epiphytic growth. Proc Nat Acad Sci U S A. 2006;103:13186-91. https://doi.org/10.1073/pnas.0603530103

62. Gardes M, Bruns TD. ITS primers with enhanced specificity for Basidiomycetes - application to the identification of mycorrhizae and rusts. Mol Ecol. 1993;2:113-8. https://doi.org/10.1111/j.1365-294X.1993.tb00005.x

63. White TJ, Bruns T, Lee S, Taylor JW. Amplification and direct sequencing of fungal ribosomal RNA genes for phylogenetics. In: Innis M, Gelfand D, Sninsky J, White T, editors. PCR protocols: a guide to methods and applications. New York: Academic; 1990. p. 315-22.

64. Ihrmark K, Bödeker ITM, Cruz-Martinez K, Friberg H, Kubartova A, Schenck J, et al. New primers to amplify the fungal ITS2 region-evaluation by 454-sequencing of artificial and natural communities. FEMS Microbiol Ecol. 2012;82:666-77. https://doi.org/10.1111/j.1574-6941.2012.01437.x

65. Caporaso JG, Kuczynski J, Stombaugh J, Bittinger K, Bushman FD, Costello EK, et al. QIIME allows analysis of high-throughput community sequencing data. Nat Methods. 2010;7:335-6. https://doi.org/10.1038/nmeth.f.303

66. Bengtsson-Palme J, Ryberg M, Hartmann M, Branco S, Wang Z, Godhe A, et al. Improved software detection and extraction of ITS1 and ITS2 from ribosomal ITS sequences of fungi and other eukaryotes for analysis of environmental sequencing data. Methods Ecol Evol. 2013;4:914-9. https:// doi.org/10.1111/2041-210X.12073
67. Schloss PD, Westcott SL, Ryabin T, Hall JR, Hartmann M, Hollister EB, et al. Introducing mothur: open-source, platform-independent, communitysupported software for describing and comparing microbial communities. Appl Environ Microbiol. 2009;75:7537-41. https://doi.org/10.1128/AEM. 01541-09

68. Kõljalg U, Nilsson RH, Abarenkov K, Tedersoo L, Taylor AFS, Bahram M, et al. Towards a unified paradigm for sequence-based identification of fungi. Mol Ecol. 2013;22:5271-7. https://doi.org/10.1111/mec.12481

69. Edgar RC. UPARSE: highly accurate OTU sequences from microbial amplicon reads. Nat Methods. 2013;10:996-8. https://doi.org/10.1038/NMETH.2604

70. UNITE community. UNITE USEARCH/UTAX release for Fungi. Version 18.11, vol. 2019; 2018. https://doi.org/10.15156/BIO/786345

71. Edgar RC. SINTAX: a simple non-Bayesian taxonomy classifier for $16 \mathrm{~S}$ and ITS sequences. bioRxiv. 2016; https://doi.org/10.1101/074161

72. Peay KG, Russo SE, McGuire KL, Lim Z, Chan JP, Tan S, et al. Lack of host specificity leads to independent assortment of dipterocarps and ectomycorrhizal fungi across a soil fertility gradient. Ecol Lett. 2015;18:80716. https://doi.org/10.1111/ele.12459

73. Development R. Core team. R: a language and environment for statistical computing. Vienna, Austria: R Foundation for Statistical. Computing. 2016; Retrieved from http://www.R-project.org

74. Shannon P, Markiel A, Ozier O, Baliga NS, Wang JT, Ramage D, et al. Cytoscape: a software environment for integrated models of biomolecular interaction networks. Genome Res. 2003;13:2498-504. https://doi.org/10. 1101/gr.1239303

75. Marquitti FMD, Guimarães PR, Pires MM, Bittencourt LF. MODULAR: software for the autonomous computation of modularity in large network sets. Ecography. 2014;37:221-4. https://doi.org/10.1111/j.1600-0587.2013.00506.x

76. Pohlert T. The pairwise multiple comparison of mean ranks package (PMCMR). R package version 4.1. 2014. http://cran.r-project.org/package= PMCMR.

77. Kolde R. pheatmap: Pretty heatmaps. R package version 1.0.8. 2015. http:// cran.rproject.org/package=pheatmap.

78. Roberts DW. Labdsv: ordination and multivariate analysis for ecology. $R$ package version 1.8-0. 2016. http://cran.r-project.org/package=labdsv.

79. Clarke KR, Somerfield PJ, Chapman MG. On resemblance measures for ecological studies, including taxonomic dissimilarities and a zero-adjusted Bray-Curtis coefficient for denuded assemblages. J Exp Mar Biol Ecol. 2006; 330:55-80. https://doi.org/10.1016/j.jembe.2005.12.017

80. Oksanen J, Blanchet FG, Friendly M, Kindt R, Legendre P, McGlinn D, et al. vegan: community ecology package. R package version 2.4-1. 2016. http:// cran.r-project.org/package=vegan.

81. Blüthgen N, Menzel F, Hovestadt T, Fiala B, Blüthgen N. Specialization, constraints, and conflicting interests in mutualistic networks. Curr Biol. 2007; 17:341-6. https://doi.org/10.1016/j.cub.2006.12.039

82. Dormann CF, Fründ J, Blüthgen N, Gruber B. Indices, graphs and null models: analyzing bipartite ecological networks. The Open Ecol J. 2009;2:724. https://doi.org/10.2174/1874213000902010007

83. Benjamini $Y$, Hochberg Y. Controlling the false discovery rate: a practical and powerful approach to multiple testing. J R Stat Soc B. 1995;85:289-300.

84. Tylianakis JM, Tscharntke T, Lewis OT. Habitat modification alters the structure of tropical host-parasitoid food webs. Nature. 2007;445:202-5. https://doi.org/10.1038/nature05429

85. Barber MJ. Modularity and community detection in bipartite networks. Phys Rev E. 2007;76:066102. https://doi.org/10.1103/PhysRevE.76.066102

86. Almeida-Neto $M$, Ulrich W. A straightforward computational approach for measuring nestedness using quantitative matrices. Environ Model Softw. 2011;26:173-8. https://doi.org/10.1016/j.envsoft.2010.08.003

87. Stone $L$, Roberts A. The checkerboard score and species distributions. Oecologia. 1990;85:74-9. https://doi.org/10.1007/BF00317345

88. Guimerà R, Amaral LAN. Cartography of complex networks: modules and universal roles. J Stat Mech-Theory E. 2005;2005:P02001. https://doi.org/10. 1088/1742-5468/2005/02/P02001

89. Ulrich W, Almeida-Neto M, Gotelli NJ. A consumer's guide to nestedness analysis. Oikos. 2009;118:3-17. https://doi.org/10.1111/j.1600-0706.2008. 17053.x 